\title{
Effect of Nonlinearity in the CMFB Circuit that Uses the Differential-Difference Amplifier ${ }^{*}$
}

\author{
Mo M. Zhang \\ Department of Electrical and Computer Engineering \\ University of California \\ Davis, CA USA \\ mmzh@ucdavis.edu
}

\author{
Paul J. Hurst \\ Department of Electrical and Computer Engineering \\ University of California \\ Davis, CA USA \\ phurst@ieee.org
}

\begin{abstract}
This paper considers one type of common-mode feedback (CMFB) circuit that uses two differential pairs to sense the common-mode output voltage $\left(V_{o c}\right)$ of a fully differential op amp. Analysis of the circuit and simulation show that even powers of the differential-mode output voltage $\left(V_{\text {od }}\right)$ affect the common-mode control signal generated by the CMFB circuit. As a result, undesired tones appear in $V_{o c}$ and $V_{\text {od }}$ due to transistor nonlinearity in the CMFB circuit. SPICE simulation results show that adding degeneration resistors to the differential pairs reduces the undesirable tones significantly.
\end{abstract}

\section{INTRODUCTION}

Fully differential (FD) operational amplifiers (op amps) are widely used in integrated circuits because they provide larger output voltage swing than single-ended circuits, they reject common-mode noise, and they have no even-order nonlinearities in the output if the circuit is balanced [1]. However, the drawback of FD circuits is that common-mode feedback (CMFB) circuitry is needed to set the commonmode voltage at the op-amp output. The CMFB circuitry senses the CM output voltage and uses negative feedback to set the CM output voltage to a value that maximizes the opamp output voltage swing.

This paper focuses on one particular type of CMFB circuit that uses two differential pairs. It is sometimes referred to as the Differential-Difference Amplifier (DDA) [2][3]. Advantages of this CMFB circuit include that it exhibits large transconductance [1] and it does not resistively load the op-amp output [2]. However, large signal analysis and simulation results presented in this paper demonstrate problems with nonlinearity in the CMFB circuit and the presence of undesired tones in the op-amp common-mode (CM) and differential-mode (DM) output voltages stemming from this nonlinearity. Finally, degeneration resistors are shown to improve the performance of the CMFB circuit.

\section{ANALYSIS OF CMFB CIRCUIT}

\section{A. Small Signal Analysis}

The schematic of a CMFB circuit using DDA is shown in

* This research was supported in part by UC MICRO Grants 04-049 and 04085 .

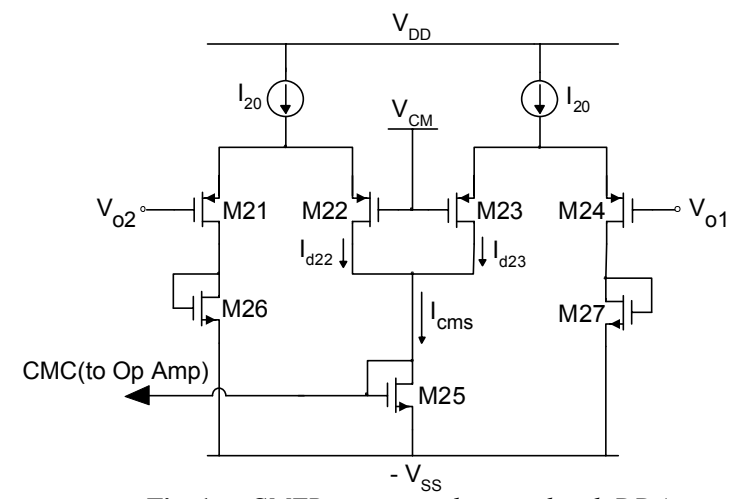

Fig. 1a. $C M F B$ circuit implemented with $D D A$.

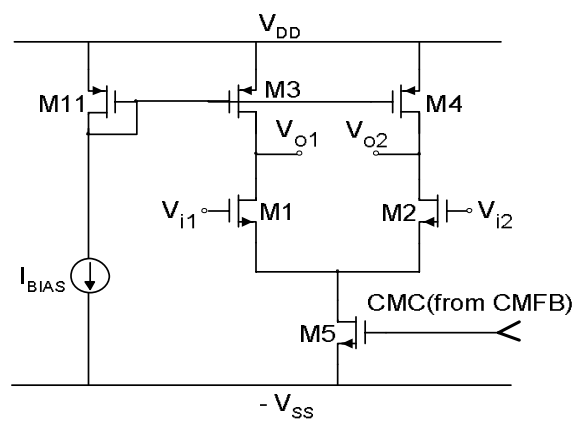

Fig. 1b. Simple op amp that uses the CMFB in Fig. 1a.

Fig. 1a. The matched differential pairs M21-22 and M23-24 connect to the op-amp outputs $\mathrm{V}_{\mathrm{o} 1}$ and $\mathrm{V}_{\mathrm{o} 2}$, sense the $\mathrm{CM}$ output voltage $\left[\mathrm{V}_{\mathrm{oc}}=\left(\mathrm{V}_{\mathrm{ol}}+\mathrm{V}_{\mathrm{o} 2}\right) / 2\right]$ of the op amp, and compare $\mathrm{V}_{\mathrm{oc}}$ with the desired $\mathrm{CM}$ output voltage, $\mathrm{V}_{\mathrm{CM}}$. A negative feedback loop sets $V_{o c}$ to be about equal to $V_{C M}$ by adjusting a bias current in the op amp that is related to the CM control-signal output of the CMFB circuit, which is $I_{c m s}$ in Fig. 1a.

The basic operation of the CMFB circuit can be illustrated by modeling M21-24 as ideal, linear transconducting elements. Since the drain current in M25 comes from the drain currents of M22 and M23, we get: 


$$
\mathrm{I}_{\mathrm{d} 25}=\mathrm{I}_{\mathrm{cms}}=\mathrm{I}_{20}+\mathrm{g}_{\mathrm{m}}\left(\mathrm{V}_{\mathrm{oc}}-\mathrm{V}_{\mathrm{CM}}\right)=\mathrm{I}_{20}+\mathrm{g}_{\mathrm{m}} \mathrm{V}_{\mathrm{err}}
$$

where $g_{m}$ is the small signal transconductance of M21-24 and $\mathrm{V}_{\text {err }}=\mathrm{V}_{\mathrm{oc}}-\mathrm{V}_{\mathrm{CM}}$. A simple op amp that uses this CMFB circuit is shown in Fig. 1b. It is composed of NMOS input differential pair M1-2, PMOS active loads M3-4, and NMOS current source M5. In this op amp, $\mathrm{I}_{\mathrm{d} 5}=2 \mathrm{I}_{\mathrm{cms}}$. Using negative feedback, the CMFB circuit adjusts $\mathrm{I}_{\mathrm{d} 5}$ so that $\mathrm{V}_{\mathrm{oc}} \approx$ $\mathrm{V}_{\mathrm{CM}}$.

\section{B. Large Signal Analysis}

Assuming transistors M21-24 in Fig. 1a are matched and operate in the saturation region with drain current given by the widely used square-law expression [4], large-signal analysis in [5] shows that the drain currents of transistors M22 and M23 are given by

$$
\begin{aligned}
& -I_{\mathrm{d} 22}=\frac{\mathrm{I}_{20}}{2}+\frac{\mathrm{K}}{2}\left(\mathrm{~V}_{\mathrm{o} 2}-\mathrm{V}_{\mathrm{CM}}\right) \sqrt{4 \mathrm{~V}_{\mathrm{ov}}^{2}-\left(\mathrm{V}_{\mathrm{o} 2}-\mathrm{V}_{\mathrm{CM}}\right)^{2}} \\
& -\mathrm{I}_{\mathrm{d} 23}=\frac{\mathrm{I}_{20}}{2}+\frac{\mathrm{K}}{2}\left(\mathrm{~V}_{\mathrm{o} 1}-\mathrm{V}_{\mathrm{CM}}\right) \sqrt{4 \mathrm{~V}_{\mathrm{ov}}^{2}-\left(\mathrm{V}_{\mathrm{o} 1}-\mathrm{V}_{\mathrm{CM}}\right)^{2}}
\end{aligned}
$$

where $\mathrm{K}=0.5 \mu \mathrm{C}_{\mathrm{ox}} \mathrm{W} / \mathrm{L}$ and $\mathrm{V}_{\mathrm{ov}}=\sqrt{\mathrm{I}_{20} / 2 \mathrm{~K}}$. Note that (2a) and (2b) are only valid when M21-24 operate in the saturation region, which requires:

$$
\left|\mathrm{V}_{\mathrm{o} 1}-\mathrm{V}_{\mathrm{CM}}\right|,\left|\mathrm{V}_{\mathrm{o} 2}-\mathrm{V}_{\mathrm{CM}}\right| \leq \sqrt{2} \mathrm{~V}_{\mathrm{ov}}
$$

Using $\mathrm{V}_{\mathrm{o} 1}=\mathrm{V}_{\mathrm{oc}}+\mathrm{V}_{\mathrm{od}} / 2, \mathrm{~V}_{\mathrm{o} 2}=\mathrm{V}_{\mathrm{oc}}-\mathrm{V}_{\mathrm{od}} / 2, \mathrm{~V}_{\mathrm{err}}=\mathrm{V}_{\mathrm{oc}}-\mathrm{V}_{\mathrm{CM}}$, and assuming $\left|\mathrm{V}_{\text {err }}\right|<<\left|\mathrm{V}_{\text {od }}\right|$, (2a) and (2b) become

$$
\begin{aligned}
& -I_{\mathrm{d} 22} \approx \frac{\mathrm{I}_{20}}{2}+\frac{\mathrm{K}}{2}\left(\mathrm{~V}_{\text {err }}-\frac{\mathrm{V}_{\text {od }}}{2}\right)\left(2 \mathrm{~V}_{\mathrm{ov}}\right) \sqrt{1-\frac{\left(\left(\frac{\mathrm{V}_{\text {od }}}{2}\right)^{2}-\mathrm{V}_{\text {err }} \mathrm{V}_{\mathrm{CM}}\right)}{4 \mathrm{~V}_{\mathrm{ov}}^{2}}} \\
& -\mathrm{I}_{\mathrm{d} 23} \approx \frac{\mathrm{I}_{20}}{2}+\frac{\mathrm{K}}{2}\left(\mathrm{~V}_{\text {err }}+\frac{\mathrm{V}_{\text {od }}}{2}\right)\left(2 \mathrm{~V}_{\mathrm{ov}}\right) \sqrt{1-\frac{\left(\left(\frac{\mathrm{V}_{\text {od }}}{2}\right)^{2}+\mathrm{V}_{\text {err }} \mathrm{V}_{\mathrm{CM}}\right)}{4 \mathrm{~V}_{\text {ov }}^{2}}}
\end{aligned}
$$

Carrying out Taylor series expansions of (4a) and (4b) using $\sqrt{1-x} \approx 1-x / 2-x^{2} / 8-x^{3} / 16-5 x^{4} / 128-\ldots, \quad$ with $x=\left[\left(\mathrm{V}_{\text {od }} / 2\right)^{2}-\mathrm{V}_{\text {err }} \mathrm{V}_{\mathrm{CM}}\right] / 4 \mathrm{~V}_{\text {ov }}^{2}$ in (4a) and $x=\left[\left(\mathrm{V}_{\text {od }} / 2\right)^{2}+\mathrm{V}_{\text {err }} \mathrm{V}_{\mathrm{CM}}\right] / 4 \mathrm{~V}_{\text {ov }}^{2}$ in (4b), keeping the first five terms in the expansions, and summing the resulting series; $\mathrm{I}_{\mathrm{cms}}=\mathrm{I}_{\mathrm{d} 25}$ can be expressed as

$$
\begin{aligned}
\mathrm{I}_{\mathrm{d} 25}=\mathrm{I}_{\mathrm{cms}}= & -\left(\mathrm{I}_{\mathrm{d} 22}+\mathrm{I}_{\mathrm{d} 23}\right) \approx \mathrm{I}_{20}+2 \mathrm{KV}_{\mathrm{ov}} \mathrm{V}_{\text {err }} \\
& \times\left[1-a_{2} \mathrm{~V}_{\text {od }}^{2}-a_{4} \mathrm{~V}_{\text {od }}^{4}-a_{6} \mathrm{~V}_{\text {od }}^{6}-a_{8} \mathrm{~V}_{\text {od }}^{8}-\ldots\right]
\end{aligned}
$$

where

$$
\begin{aligned}
& a_{2} \approx \frac{3}{32 \mathrm{~V}_{\mathrm{ov}}^{2}}+\frac{\mathrm{V}_{\mathrm{err}}^{2}}{128 \mathrm{~V}_{\mathrm{ov}}^{4}} \\
& a_{4} \approx \frac{5}{2048 \mathrm{~V}_{\mathrm{ov}}^{4}}+\frac{5 \mathrm{~V}_{\mathrm{err}}^{2}}{4096 \mathrm{~V}_{\mathrm{ov}}^{6}}+\frac{5 \mathrm{~V}_{\mathrm{err}}^{4}}{32768 \mathrm{~V}_{\mathrm{ov}}^{8}} \\
& a_{6} \approx \frac{7}{65536 \mathrm{~V}_{\mathrm{ov}}^{6}}+\frac{35 \mathrm{~V}_{\mathrm{err}}^{2}}{262144 \mathrm{~V}_{\mathrm{ov}}^{8}} \\
& a_{8} \approx \frac{45}{8388608 \mathrm{~V}_{\mathrm{ov}}^{8}}
\end{aligned}
$$

If $\left|V_{\text {od }}\right|<<\left|V_{\text {ov }}\right|$, then the even-order $V_{\text {od }}$ terms in (5) become insignificant and (5) agrees with (1) $\left[\mathrm{g}_{\mathrm{m}}=2 \mathrm{KV}_{\mathrm{ov}}\right.$ for transistors operating in saturation]. However, having $\mathrm{V}_{\text {od }}$ with significantly large magnitude so that (1) is no longer valid is quite reasonable, since op amps usually produce large differential output voltages. In this case, (5) clearly indicates that the DM output voltage $\mathrm{V}_{\text {od }}$ affects the current $\mathrm{I}_{\mathrm{cms}}$ produced by the CMFB circuit. This is undesirable since ideally the CMFB circuit would generate a current $\mathrm{I}_{\mathrm{cms}}$ that is related to $V_{\text {err }}$ but not to $V_{\text {od }}$ and the CMFB loop would drive $V_{\text {err }}$ to zero and hence $V_{\text {oc }}$ to $V_{C M}$. As shown in (5), $I_{\text {cms }}$ here is a nonlinear function of the DM output voltage $\left(\mathrm{V}_{\mathrm{od}}\right)$, and thus a time-varying $\mathrm{V}_{\text {od }}$ can cause the op amp to have a timevarying bias current $\mathrm{I}_{\mathrm{d} 5}=2 \mathrm{I}_{\text {cms. }}$. A time-varying bias current will affect the op-amp outputs, particularly when $V_{\text {od }}$ is large. Also, a small DC level shift occurs due to the contribution of all the even nonlinearity terms so that $\mathrm{V}_{\mathrm{oc}}(\mathrm{DC}) \neq \mathrm{V}_{\mathrm{CM}}$.

\section{Simulation Results}

\section{A. Comparing (5) with (2) and SPICE}

Due to finite CMFB loop gain, $\mathrm{V}_{\mathrm{oc}}$ is not exactly $\mathrm{V}_{\mathrm{CM}}$ as desired. Therefore, according to (5), the op-amp DM output, $V_{\text {od }}$, affects the current $I_{c m s}$ and causes $V_{\text {oc }}$ not to be constant if $V_{\text {od }}$ is not constant. First, to verify its accuracy, (5) was simulated in MATLAB and the results were compared with $I_{c m s}$ given by the sum of (2a) and (2b) for which no approximation was applied. The simulation parameters were $\mathrm{I}_{20}=100 \mu \mathrm{A},(\mathrm{W} / \mathrm{L})_{21-24}=6 \mu \mathrm{m} / 0.8 \mu \mathrm{m}$, and $\mathrm{k}_{\mathrm{p}}=\mu_{\mathrm{p}} \mathrm{C}_{\mathrm{ox}}=$ $59.2 \mu \mathrm{A} / \mathrm{V}^{2}$. It was found that for the $\mathrm{V}_{\text {od }}$ range that satisfies (3), (5) agrees with the sum of (2a) and (2b) with an error less than $0.03 \%$ for $\mathrm{V}_{\text {err }}=0.01 \mathrm{~V}$ and $1.00 \%$ for $\mathrm{V}_{\text {err }}=0.1 \mathrm{~V}$.

To further examine the validity of (5), the CMFB circuit in Fig. 1a was simulated in SPICE using level 3 models for a $0.35 \mu \mathrm{m}$ CMOS process with $\mathrm{V}_{\mathrm{DD}}=\mathrm{V}_{\mathrm{SS}}=1.65 \mathrm{~V}, \mathrm{~V}_{\mathrm{CM}}=0 \mathrm{~V}$, $\mathrm{V}_{\text {od }}$ was a $10 \mathrm{kHz}$ sine wave with amplitude in the range of $0 \mathrm{~V}$ to $1.16 \mathrm{~V}$ (to keep all transistors in the saturation region), $\mathrm{I}_{20}=100 \mu \mathrm{A}, \quad(\mathrm{W} / \mathrm{L})_{21-24}=6 \mu \mathrm{m} / 0.8 \mu \mathrm{m}, \quad(\mathrm{W} / \mathrm{L})_{25}=$ $16 \mu \mathrm{m} / 0.8 \mu \mathrm{m}$ and $(\mathrm{W} / \mathrm{L})_{26,27}=8 \mu \mathrm{m} / 0.8 \mu \mathrm{m}$. A Fast-Fourier Transformation (FFT) was performed on the CM sense current, $\mathrm{I}_{\mathrm{cms}}$, obtained from both SPICE and MATLAB simulations, and the FFT spectra are shown in Fig. 2 for $\left(\mathrm{V}_{\mathrm{od}}\right)_{\mathrm{pk}}=1.16 \mathrm{~V}$. The two plots are virtually identical; they coincide almost everywhere except for the low-amplitude noise in the spectrum from SPICE at 50, 70, 80 and $90 \mathrm{kHz}$, which we believe is due to 'numerical noise' in the SPICE 


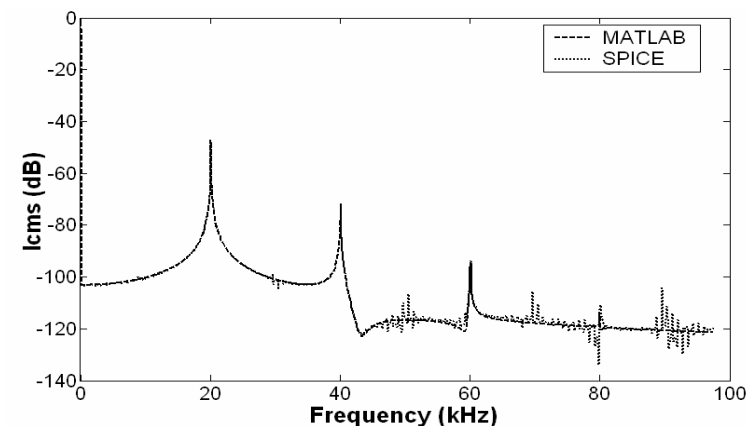

Fig. 2. FFT spectra of $I_{c m s}$ from MATLAB and SPICE Simulations

simulation. This close agreement implies that (5) accurately predicts the CMFB circuit performance for the signal range that keeps the CMFB transistors in the saturation region.

\section{B. Closed CMFB Loop Simulation}

To form a CMFB loop, the gates of the transistors M25 and M5 in Fig. 1a and 1b, respectively, are connected to form the current mirror that controls the bias current in the simple op amp. The simulation parameters for the CMFB circuit and the SPICE models given in the previous section were used. In addition, for the op amp in Fig. $1 \mathrm{~b}, \mathrm{~V}_{\mathrm{DD}}=\mathrm{V}_{\mathrm{SS}}$ $=1.65 \mathrm{~V}, \mathrm{~V}_{\text {ic }}=0 \mathrm{~V}, \mathrm{I}_{\mathrm{BIAS}}=100 \mu \mathrm{A},(\mathrm{W} / \mathrm{L})_{1,2}=19 \mu \mathrm{m} / 1.4 \mu \mathrm{m}$, $(\mathrm{W} / \mathrm{L})_{3,4,11}=3.2 \mu \mathrm{m} / 0.8 \mu \mathrm{m}$ and $(\mathrm{W} / \mathrm{L})_{5}=32 \mu \mathrm{m} / 0.8 \mu \mathrm{m}$.

Fig. 3 shows the FFT spectra of $V_{o c}$ and $V_{\text {od }}$ with an opamp DM sinusoidal input at $10 \mathrm{kHz}$ with $\left(\mathrm{V}_{\mathrm{id}}\right)_{\mathrm{pk}}=11 \mathrm{mV}$ that gives $\left(\mathrm{V}_{\mathrm{od}}\right)_{\mathrm{pk}}=1.16 \mathrm{~V}$, which causes the transistors in the CMFB circuit to operate on the edge of saturation at the output swing limits. Ideally, $\mathrm{V}_{\mathrm{oc}}$ would be constant and $\mathrm{V}_{\mathrm{od}}$ would be a $10 \mathrm{kHz}$ signal. Additional simulations showed that the undesired tones in Fig. 3 are more than $10 \mathrm{~dB}$ smaller when an ideal CMFB circuit is used. Therefore, nonlinearity in the CMFB circuit in Fig. 1a is the dominant cause of the undesired tones in the $\mathrm{V}_{\mathrm{oc}}$ and $\mathrm{V}_{\text {od }}$ spectra in Fig. 3. Noticeable undesired tones appear here since the magnitude of $\mathrm{V}_{\text {od }}$ is greater than $\left(\mathrm{V}_{\mathrm{ov}}\right)_{21-24}=0.475 \mathrm{~V}$. The presence of odd harmonics in the $\mathrm{V}_{\text {od }}$ spectrum can be explained as follows. The DM output of the op amp is given by

$$
\mathrm{V}_{\text {od }}=\mathrm{A}_{\mathrm{dm}} \mathrm{V}_{\text {id }}=-\left(\mathrm{g}_{\mathrm{m}} \mathrm{R}_{\mathrm{o}}\right) \mathrm{V}_{\text {id }}
$$

where $g_{m}$ is the small-signal transconductance of the op amp, and $R_{0}$ is the op-amp output resistance. Based on smallsignal analysis [5], $g_{m}$ is proportional to $\left(I_{d 5}\right)^{1 / 2}$ and $R_{0}$ is inversely proportional to $\mathrm{I}_{\mathrm{d} 5}$. Hence, the $\mathrm{DM}$ gain, $\mathrm{A}_{\mathrm{dm}}$, is inversely proportional to $\left(\mathrm{I}_{\mathrm{d} 5}\right)^{1 / 2}$. Since (5) shows that the opamp bias current, $I_{d 5}$, contains even-order terms of $V_{o d}, A_{d m}$ is a function of even-order terms of $\mathrm{V}_{\text {od. }}$. Using this result in (7), it can be shown that $V_{\text {od }}$ is an odd function of $V_{\text {id }}$, i.e.,

$$
\mathrm{V}_{\text {od }}=\mathrm{b}_{1} \mathrm{~V}_{\text {id }}+\mathrm{b}_{3} \mathrm{~V}_{\mathrm{id}}^{3}+\mathrm{b}_{5} \mathrm{~V}_{\mathrm{id}}^{5}+\cdots
$$

Fig. 3b shows that $V_{\text {od }}$ contains $V_{\text {id }}$ amplified (i.e., the tone at $10 \mathrm{kHz}$ ) and odd harmonics of $\mathrm{V}_{\mathrm{id}}$, in agreement with (8). So based on analysis and simulation, nonlinearity in the
CMFB circuit can cause undesired tones to appear in the opamp DM and CM outputs.

\section{Device Mismatch}

When transistors M21-24 are matched, only even harmonics of $\mathrm{V}_{\text {od }}$ appear in $\mathrm{I}_{\mathrm{cms}}$ and $\mathrm{V}_{\text {oc }}$ as shown in (5) and Fig. 3a, respectively. However, with device mismatch, both odd and even powers of $V_{o d}$ affect $I_{c m s}$ and therefore $V_{o c}$. Figure 4 shows the FFT spectra of $\mathrm{V}_{\mathrm{oc}}$ and $\mathrm{V}_{\text {od }}$ with worst case mismatch of $2 \%$ introduced in each differential pair in the CMFB circuit. Transistor mismatch in the CMFB circuit does not significantly affect the spectrum of $\mathrm{V}_{\text {od }}$ or that of the even harmonics of $10 \mathrm{kHz}$ in $\mathrm{V}_{\mathrm{oc}}$. However, comparing with Fig. 3, simulation results reveal that odd harmonics of the $10 \mathrm{kHz}$ op-amp DM input signal with noticeable magnitudes appear in $\mathrm{V}_{\mathrm{oc}}$.
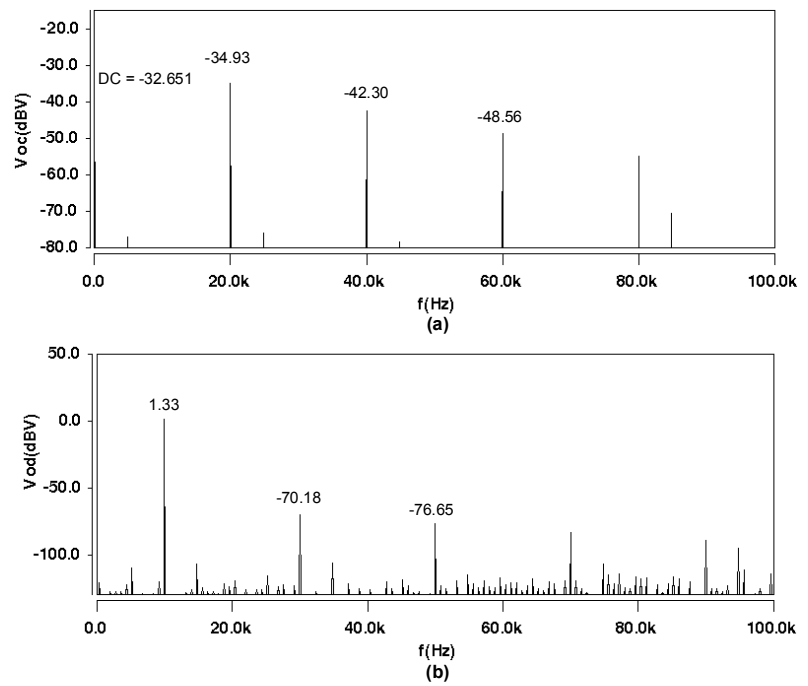

Fig. 3. FFT spectra of (a) $V_{o c}$ and (b) $V_{\text {od }}$ with closed CMFB loop
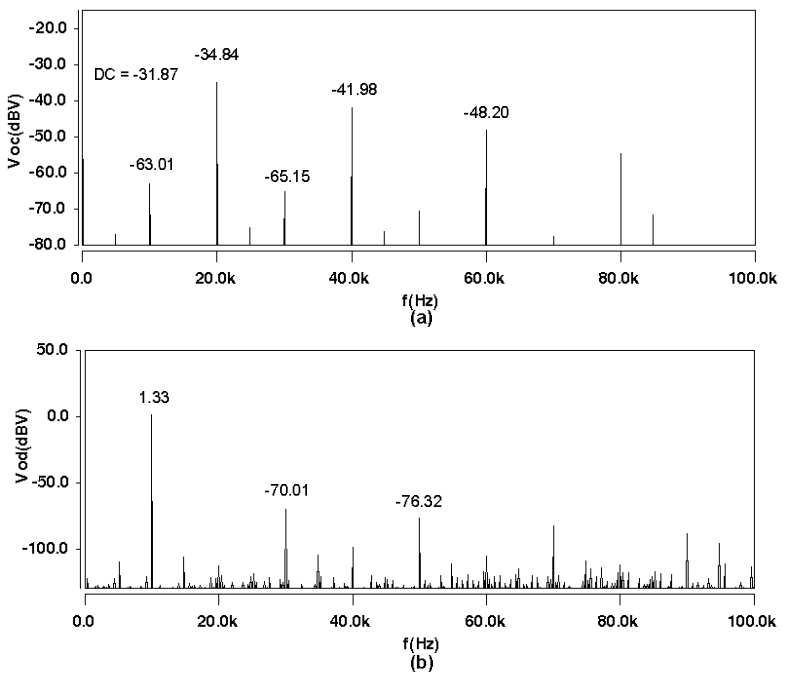

Fig. 4. FFT spectra of (a) $V_{o c}$ and (b) $V_{o d}$ with $2 \%$ device mismatch in the CMFB circuit with closed CMFB loop 


\section{CMFB CIRCUIT WITH DEGENERATION RESISTORS}

\section{A. Adding Resistors}

Using long channel devices for the differential pair transistors M21-24 in the CMFB will provide better linearity in the CMFB circuit. However, to avoid large capacitance from the resulting large devices, degeneration resistors can be used instead to improve the linearity of the differential pairs as shown in Fig. 5. With degeneration resistors, the loop gain of the CMFB circuit is reduced by $1+\mathrm{g}_{\mathrm{m}} \mathrm{R} / 2$, where $\mathrm{R}$ is the degeneration resistance in Fig. 5 and $\mathrm{g}_{\mathrm{m}}$ is the small signal transconductance of M21-24. To maintain the same CMFB loop gain with the addition of degeneration resistors, the current gain of mirror M25-M5 can be increased by increasing the $\mathrm{W} / \mathrm{L}$ ratio of transistor M5. In addition, the resulting extra bias current can be removed in the op amp by a DC current source $I_{\text {DRAW }}$ as shown in Fig. 5.

\section{B. Simulation Results}

The circuit in Fig. 5 was simulated in SPICE with the parameters described above. Degeneration resistance $\mathrm{R}=$ $70 \mathrm{k} \Omega$ and $\mathrm{I}_{\text {DRAW }}=890 \mu \mathrm{A}$ were used. The M5-M25 current gain was increased from 2 to 11 . Fig. 6 shows the spectra of $\mathrm{V}_{\mathrm{oc}}$ and $\mathrm{V}_{\mathrm{od}}$. Compared to Fig. 4, the magnitudes of the undesired tones in the $\mathrm{V}_{\mathrm{oc}}$ and $\mathrm{V}_{\mathrm{od}}$ spectra are reduced. Based on additional simulations, the harmonics in $V_{\text {od }}$ in Fig. $6 \mathrm{~b}$ are now dominated by distortion caused by the transistors in the op amp. The CMFB circuit has been linearized by the degeneration resistors, and the undesired tones caused by nonlinearity in the CMFB circuit have been reduced.

\section{CONCLUSION}

Large signal analysis of the CMFB circuit that uses two differential pairs has been presented. Ideally, the CMFB loop gain is infinite, the CMFB drives $\mathrm{V}_{\text {oc }}$ to $\mathrm{V}_{\mathrm{CM}}$, and $\mathrm{V}_{\text {err }}$ is zero. However, in practice $\mathrm{V}_{\text {err }}$ is not zero. In that case, both analysis and simulation illustrate that even powers of $\mathrm{V}_{\text {od }}$ can affect the output of the CMFB circuit in Fig. 1a and can introduce undesired tones in the CM and DM outputs of an op amp that uses this CMFB circuit. If mismatch is present in the CMFB circuit, simulations show that additional undesired tones will be generated. SPICE simulations verified that degeneration resistors added in the CMFB circuit improve the linearity of the CMFB circuit and reduce the magnitude of the undesirable tones in the op-amp outputs.

\section{REFERENCES}

[1] J. F. Duque-Carrillo. "Control of the common-mode component in CMOS continuous-time fully differential signal processing," Analog Integrated Circuits and Signal Processing, An International Journal, Kluwer Academic Publishers, pp. 131-140, September 1993.

[2] L. Luh, J. Choma, Jr., and J. Draper. "A continuous-time commonmode feedback circuit (CMFB) for high-impedance current mode application," IEEE Trans. on Circuits and Systems II, Vol. 47, Issue 4, pp. 363-369, April 2000.
[3] Z. Czarnul, S. Takagi and N. Fujii. "Common-mode feedback circuit with Differential-Difference Amplifier," IEEE Trans. on Circuits and Systems I, Vol. 41, No. 3, pp. 243-246, March 1994.

[4] D. Johns and K. Martin, Analog Integrated Circuit Design, New York, NY., John Wiley and Sons, 1997.

[5] P. R. Gray, P. J. Hurst, S. H. Lewis, and R. G. Meyer, Analysis and Design of Analog Integrated Circuits, $4^{\text {th }}$ edition, New York, NY., John Wiley and Sons, 2001.

[6] D. Hernandez-Garduno and J. Silva-Martinez. "Continuous-time common-mode feedback for high-speed switched-capacitor networks," IEEE Journal of Solid-State Circuits, Vol. 40, No. 8, pp. 1610-1617, August 2005.

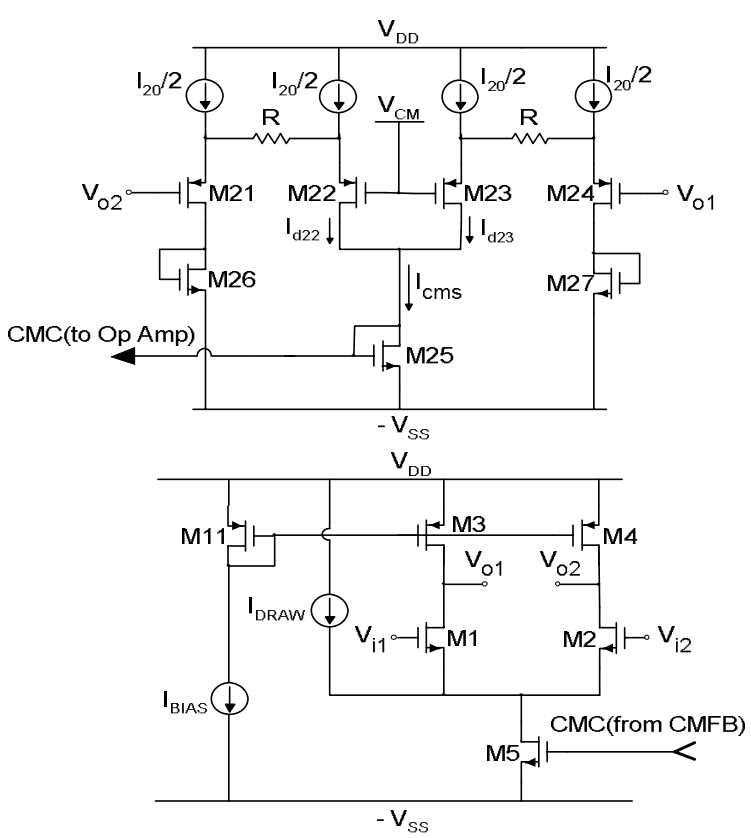

Fig. 5. Modified CMFB circuit with degeneration resistors (top) and op amp (bottom) with $I_{D R A W}$ added.
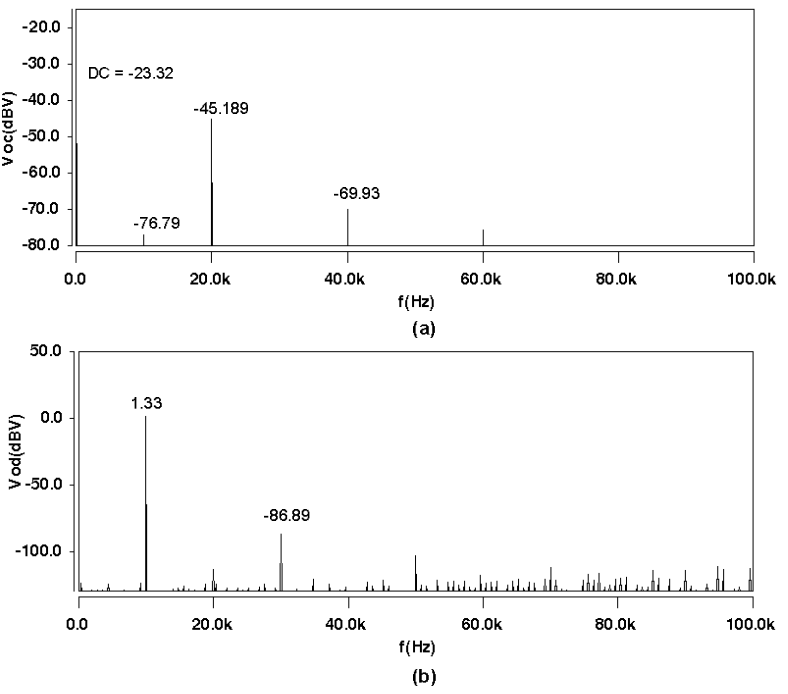

Fig. 6. FFT spectra of (a) $V_{o c}$ and (b) $V_{o d}$ with degeneration resistors added to CMFB circuit 